\title{
МЕТОДИЧЕСКИЕ РЕКОМЕНДАЦИИ ПО ВНЕДРЕНИЮ СТАНДАРТА ISO 45001 НА ПРЕДПРИЯТИИ
}

\section{METHODOLOGICAL RECOMMENDATIONS FOR THE IMPLEMENTATION OF THE ISO 45001 STANDARD IN THE ENTERPRISE \\ B. Sevastyanov \\ R. Shadrin \\ E. Ali \\ V. Lisin}

Summary: Introduction. The article discusses the issues of certification of production according to the ISO 45001 standard, shows the relevance of the transition to this standard, which consists in ensuring the effectiveness of the functioning of the labor protection management system as part of the enterprise management system.

Problem statement. The objective of the study is to develop guidelines for the implementation of the ISO 45001 standard at the enterprise.

Theoretical part. The development of methodological material is based on the experience of implementing the ISO 45001 standard in a number of enterprises in the Udmurt Republic. In the course of the work, a comparative analysis of ISO 45001 with the provisions of the standard of the previous generation was carried out, fundamental differences were highlighted. The main stages of implementation are shown, organizational and management solutions for the successful implementation of the project are proposed.

Conclusions. The As a result of the work done, methodological recommendations were developed for the implementation of the ISO 45001 standard in the integrated management system of the enterprise.

Keywords: occupational safety, occupational injury, work-related injuries, provision of services to the population.
Севастьянов Борис Владимирович

Д.т.н., профессор, Ижевский государственный технический университет имени М.Т. Калашникова sbv47@mail.ru

Шадрин Роберт Олегович

К.т.н., доцент, Ижевский государственный технический университет имени М.Т. Калашникова shadrinrobert@gmail.ru

Али Елена Борисовна

К.т.н., доцент, Ижевский государственный технический университет имени М.Т. Калашникова

leb06@mail.ru

Лисин Владимир Алексеевич

Старший преподаватель, Ижевский государственный технический университет имени М.Т. Калашникова vladimirlisin2@gmail.com

Аннотация: Введение. В статье рассмотрены вопросы сертификации производства по стандарту ISO 45001, показана актуальность перехода на этот стандарт, заключающаяся в обеспечении результативности функционирования системы управления охраны труда как части системы менеджмента предприятия.

Постановка задачи. Задачей исследования является разработка методических рекомендаций по внедрению стандарта ISO 45001 на предприятии.

Теоретическая часть. Разработка методического материала основана на опыте внедрения стандарта ISO 45001 в ряде предприятий Удмуртской Республики. В ходе работы проведен сравнительных анализ ISO 45001 с положениями стандарта прошлого поколения, выделены принципиальные отличия. Показаны основные этапы внедрения, предложены организационные и управленческие решения для успешной реализации проекта.

Выводы. В результаты проделанной работы разработаны методические рекомендации по внедрению стандарта ISO 45001 в интегрированную систему менеджмента предприятия.

Ключевые слова: охрана труда, система охраны здоровья и безопасности труда, сертификация по ISO 45001, методические рекомендации по сертификации, внедрение ISO 45001, интегрированная система менеджмента.

эффективно взаимодействовать с другими структурами предприятия. Создание такой системы возможно при использовании научного подхода и передовых нормативных решений, в том числе стандарта ISO 45001.

Наиболее известными отечественными документами, регулирующими системы управления охраной труда (СУОТ) явились «Рекомендации. Система управления охраной труда. Основные положения», утвержденный Госстандартом СССР и ВЦСПС 18/21 марта 1983 года; Положение о системе управления охраной труда и техникой безопасности в Минэнерго СССР. РД 34.03.101, утвержденное Министерством энергетики и электри- 
фикации СССР 26 июня 1984 года; Типовое положение о системе управления охраной труда в лесном хозяйстве, утвержденное Государственным комитетом СССР по лесному хозяйству 21 октября 1987 года; Основные положения системы управления охраной труда на железнодорожном транспорте, утвержденное МПС СССР 14 декабря 1990 года. В советское время модель СУОТ, базирующаяся на указанных документах, послужила основой для разработки в дальнейшем систем управления охраной труда, как на отраслевых уровнях, так и на уровне предприятий СССР и существует до сих пор во многих организациях Содружества независимых государств. Структуры управления государственного и ведомственного уровня зачастую для решения задач охраны труда применяли системный подход, представители научного сообщества уделяли внимание анализу и профилактике производственного травматизма, профессиональной заболеваемости, разрабатывали мероприятия и средства по улучшению условий труда и повышению его безопасности. Очевидно, что комплексная работа такого рода позволила обеспечить системность в вопросах безопасности труда.

Актуальность разработки элементов менеджмента охраны труда состоит в обеспечении результативности функционирования системы управления охраной труда и в повышении ее эффективности в соответствии с международным стандартом ISO 45001, что в свою очередь позволит обеспечить безопасные условия труда на рабочих местах, уменьшить уровни производственного травматизма и профессиональных заболеваний, а также обеспечить выполнение работ по предупреждению аварийных ситуаций [3].

Внедрение стандарта ISO 45001 несет определенные выгоды для предприятия. Они заключаются в осуществлении контроля организации безопасности труда работников, профилактике несчастных случаев, повышении имиджа предприятия, получении возможности расширения и обретения новых рынков сбыта продукции, в том числе международных.

ISO 45001 состоит из рекомендаций по организации эффективных процессов управления безопасностью труда, универсален относительно размера и численности организации, характера и вида ее деятельности.

В стандарте ISO 45001 по сравнению со стандартом прошлого поколения и OHSAS 18001 наблюдается ряд принципиальных отличий $[5,6]$ :

- изменилась структура документа в сторону увеличения количества разделов;

- более подробно рассмотрены вопросы организации аутсорсинга, менеджмента и реализации мероприятий, направленных на непрерывное улучшение.
Основными достоинствами стандарта ISO 45001 являются:

1. ISO 45001 является стандартом со структурой «Высокого уровня», что гарантирует успешную интеграцию в систему менеджмента предприятия, основанную на других международных стандартах ISO.

2. Рекомендации по организации мероприятий, направленных на снижение уровня профессиональных рисков, в том числе средствами уведомления работниках о текущем состоянии организации безопасных условий труда и экологичности производства.

3. Повышение эффективности предприятия, в том числе экономической, за счет снижения числа негативных событий - происшествий, аварий, несчастных случаев.

4. Внедрение системы анализа и профилактики профессиональных рисков в области безопасности труда.

5. Возможностью устанавливать цели и задачи в соответствии со стандартами ISO.

Основная идея нового стандарта схожа с идеями стандарта-предшественника, ключевым отличием является новая форма. Основные изменения, вносимые стандартом ISO 45001 можно охарактеризовать следующим образом:

1. Бизнес-контекст: глава 4.1, внешние и внутренние вопросы, вводит новые пункты для систематического определения и мониторинга бизнес-контекста.

2. Работники и другие заинтересованные стороны: в главе 4.2 повышенное внимание уделяется потребностям и ожиданиям работников и других заинтересованных сторон, а также вовлечению работников. Это позволяет систематически определять и понимать факторы, которыми необходимо управлять через систему менеджмента.

3. Управление рисками и возможностями: описанное в главах 6.1.1, 6.1.2.3, 6.1.4, компании должны определять, рассматривать и, при необходимости, принимать меры по устранению любых рисков или возможностей, которые могут повлиять (положительно или отрицательно) на способность системы менеджмента достигать намеченных результатов, включая улучшение здоровья и безопасности на рабочем месте.

4. Лидерство и приверженность руководства: как указано в главе 5.1, ISO 45001 уделяет более пристальное внимание высшему руководству, которое должно активно участвовать и брать на себя ответственность за эффективность системы управления.

5. Цели и результативность: усиление внимания к целям как движущим силам для улучшений (главы 
6.2.1,6.2.2) и оценке эффективности (глава 9.1.1).

6. Расширенные требования, касающиеся:

- участие и консультации работников (5.4)

- коммуникация (7.4): более подробно предписывающая «механики» коммуникации, включая определение того, с кем, когда и как общаться.

- закупки, включая аутсорсинговые процессы, и подрядчиков (8.1.4) [7-9].

\section{Постановка задачи}

Задачей исследования является разработка методических рекомендаций по внедрению стандарта ISO 45001 на предприятии с учетом опыта организаций Удмуртской Республики.

\section{Теоретическая часть}

Предложена следующая методология, основанная на руководящих принципах стандартов ISO, которые также соответствуют требованиям ISO 45001 (рис. 1).

Методология основа на цикле Шухарта-Деминга, который разделен на четыре фазы: планирование, выполнение, проверка и действие. Каждая фаза состоит из нескольких этапов, которые делятся на действия и задачи. В предлагаемых методических рекомендациях рассматриваются ключевые этапы проекта внедрения стандарта в организации.
Следуя рекомендациям, организация может обеспечить выполнение всех минимальных требований для внедрения системы менеджмента. Ключ к успешной реализации процесса внедрения зависит от контекстуализированного и адаптируемого подхода организации.

Последовательность шагов, необходимых в процессе сертификации, может быть изменена (инвертирована или объединена) для достижения наиболее подходящего результата.

Если рассмотреть процесс сертификации более предметно, то можно выделить 6 основополагающих этапов.

1. Ознакомление с ISO 45001. На первый взгляд этот шаг может показаться очевидным, но, прежде чем стать совместимым с ISO 45001 необходимо сформировать представление о том, какие последствия влечет за собой сертификация. Убедившись в понимании отдельных требований и их значении для предприятия, можно не тратить время и ресурсы на неправильные и неэффективные действия. Независимо от того, в какой форме будет проходить подготовка к сертификации, будь то привлечение внешних специалистов или работа штатных сотрудников, в первую очередь необходимо приобрести копию стандарта и внимательно с ним ознакомиться.

2. Проведение анализа действующих систем. Прежде чем вносить какие-либо изменения в текущие процессы, необходимо провести анализ пробелов, рисков и обзор соответствия требованиям ISO 45001. Такие дей-

\begin{tabular}{|c|c|c|c|}
\hline 1.Plan & 2. Do & 3. Check & 4. Act \\
\hline $\begin{array}{l}1.1 \text { Иницинрование } \\
\text { внедрения системы } \\
\text { ОЗБТ }\end{array}$ & $\begin{array}{l}2.1 \text { Управление } \\
\text { ресурсами }\end{array}$ & $\begin{array}{l}3.1 \text { Мониторинг, } \\
\text { измерение, анализ и } \\
\text { оценка эффектнвности }\end{array}$ & $\begin{array}{l}4.1 \text { Обработка } \\
\text { инцидентов и } \\
\text { несоответствий }\end{array}$ \\
\hline $\begin{array}{l}1.2 \text { Понимание } \\
\text { организацин в еe } \\
\text { потребности }\end{array}$ & $\begin{array}{l}2.2 \text { Осведомленность и } \\
\text { коммуникация }\end{array}$ & 3.2 Внутренннй аудит & $\begin{array}{l}4.2 \text { Постоянное } \\
\text { совершенствование }\end{array}$ \\
\hline $\begin{array}{l}1.3 \text { Анализ } \\
\text { действующей системы }\end{array}$ & $\begin{array}{l}2.3 \text { Управление } \\
\text { документацией }\end{array}$ & $\begin{array}{l}3.3 \text { Обзор деятельности } \\
\text { руководства }\end{array}$ & \\
\hline $\begin{array}{l}1.4 \text { Лидерство и участие } \\
\text { работннков }\end{array}$ & $\begin{array}{l}2.4 \text { Оперативный } \\
\text { контроль }\end{array}$ & & \\
\hline $\begin{array}{l}1.5 \text { Область применения } \\
\text { снстемы менеджмента } \\
\text { ОЗБТ }\end{array}$ & & & \\
\hline $\begin{array}{l}1.6 \text { Политика н цель } \\
\text { ОЗБТ }\end{array}$ & & & \\
\hline $\begin{array}{l}1.7 \text { Выявление } \\
\text { опасностей и оценка } \\
\text { рисков и возможностей }\end{array}$ & & & \\
\hline $\begin{array}{l}1.8 \text { Правовые и другие } \\
\text { требовання }\end{array}$ & & & . \\
\hline
\end{tabular}

Рис. 1. Методология подготовки внедрения стандарта ISO 45001 на предприятии 
ствия помогут получить представление о том, в каком состоянии на данных момент находятся системы охраны здоровья и безопасности труда и что необходимо изменить для достижения целей соответствия с ISO 45001.

На данном этапе проводится анализ документации системы менеджмента с целью определения соответствия последних требованиям стандарта.

Предлагается следующий перечень документов для анализа:

- политика организации;

- руководящие документы системы менеджмента предприятия;

- структурная схема организации с указанием административных и инженерных служб, основных и вспомогательных подразделений (цехов, участков, производственных площадок);

- структурная схема службы качества проверяемой организации (если она не включена в общую структурную схему организации);

- перечень документов системы менеджмента;

- документированные процедуры, требуемые стандартами на соответствующую систему менеджмента;

- документы, необходимые организации для обеспечения эффективного планирования, осуществления процессов и управления ими в соответствии с действующим перечнем документов системы менеджмента;

- результаты внутреннего аудита;

- сведения о несчастных случаях и профессиональных заболеваниях;

- сведения о проверках государственными контрольно-надзорными органами (за последние 3 года);

- сведения об основных поставщиках сырья, материалов, комплектующих;

- перечень специальных процессов производства и обслуживания, подлежащих валидации;

- ситуационных план организации и карта-схема ее местоположения;

- программа достижения целей в области охраны здоровья и безопасности труда;

- процедура по идентификации опасностей, оценки риска и внедрения необходимых контрольных мер;

- перечень наиболее существенных воздействий на условия и охрану труда.

3. Создание плана. После проведения анализа существующих систем формируется представление о том, какие действия необходимо предпринять для осуществления совместимости с ISO 45001. Необходимо использовать полученную информацию для разработки плана действий. Примерный план представлен в таблице 1. Ряд пунктов может быть изменен, расширен/дополнен или исключен в зависимости от состояния охраны здоровья и безопасности труда на конкретном предприятии.

4. Образовательная деятельность. Разработанный план действий должен быть понят и принят в масштабах всей организации. Предоставление сотрудникам возможности обучения имеет решающее значение, так как это гарантирует получение необходимой информации для выполнения должностных обязанностей в области безопасности труда с учетом требований ISO 45001. Усилия по соблюдению требований стандарта необходимо прилагать на всех организационных уровнях. Для руководства недостаточно быть единственными людьми, участвующими в изменениях, которые необходимо внести. Если ставится цель привить позитивную культуру на долгосрочную перспективу, крайней важно предоставить сотрудникам доступ к соответствующему образованию и обучению.

5. Аудит и проверка эффективности. После начала внесения изменений в соответствии с разработанным планом, регулярный мониторинг процесса в достижении целей сертификации становится крайней важным. Проведение внутреннего аудита систем по стандарту ISO 45001 позволяет определить эффективность разработанного плана и необходимость внесения корректировок и уточнений. В дополнение к этому частое выполнение аудитов дает возможность оценить обслуживаются ли внедряемые системы. Изучение постоянного успеха или неудач прилагаемых усилий позволит оптимизировать процесс внедрения, экономить время и ресурсы, исключать те направления процесса, которые показывают низкую эффективность или не работают вовсе [10].

6. Сертификация. Заключительный этап в достижении соответствия стандарту включает в себя контакт с регистратором, который также известен как орган по сертификации. На этом этапе аттестованный аудитор органа по сертификации завершит сертификационный аудит, который проверяет, соответствует ли предприятие руководящим принципам ISO 45001. Процедуру сертификации проводят аттестованные аудиторы, основными методами аудита зачастую выступают опрос, наблюдение и оценка условий труда, контроль выполнения мероприятий в области безопасности труда, анализ и оценка вновь введённых документов.

После проверки систем сертифицирующая организация либо одобрит сертификацию, либо отклонит, возможен и третий вариант, при котором будет представлен перечень несоответствий, которые необходимо устранить.

Для соблюдения требований ISO 45001 рекомендуется организация регулярных проверок системы охраны 
Таблица 1.

Примерный план действий для осуществления совместимости с ISO 45001

1 Диагностический аудит. Анализ имеющейся системы управления. Планирование действий по проекту

1.1 Организационные мероприятия. Создание рабочей группы $\quad$ Создание регламентированных условий для выполнения проекта. Разработка, определение и утверждение регламента проекта. Утверждение участников рабочей группы проекта и взаимодействия по проекту структуры. Регламент взаимодействия определяет главные принципы проведения мероприятий и взаимодействия в границах проекта

1.2 Анализ имеющейся документации системы менеджмента организации, проверка соответствия требованиям стандарта

1.3 Оценка имеющейся системы менеджмента в границах выполнения аудита

1.4 Создание отчета по итогам аудита, доведение результатов до руководства организации

\section{2 Создание проекта системы менеджмента}

2.1 Семинар для рабочей группы организации о требованиях стандарта и принципах построения системы менеджмента

2.2 Определение процессной модели предприятия Определение насколько уровень системы менеджмента соответствует требованиям стандарта.

Отчет 06 итогах проведения аудита, включающий оценку соответствия имеющейся системы управления требованиям в сфере качества

\section{3 Документация по процессам системы менеджмента охраны здоровья и безопасности труда}

3.1 Подготовка проекта, целей и политики в области охраны здоровья и безопасности труда

3.2 Разработка необходимых стандартов организации ности труда Определение плановых и целевых показателей в сфере охраны здоровья и безопасности труда

3.3 Семинар для персонала предприятия о внутреннем аудите менеджмента охраны здоровья и безопасности труда

3.4 Составление плана-графика выполнения внутренних аудитов системы менеджмента охраны здоровья и безопасности труда

3.5 Внедрение документации системы менеджмента охраны здоровья и безопасности труда на предприятии

Подготовка внутренних аудиторов, их аттестация План-график выполнения внутренних аудитов системы менеджмента охраны здоровья и безопасности труда Официальное внедрение документации менеджмента охраны здоровья и безопасности труда на предприятии

Утвержденный комплект документов

4. Внедрение системы менеджмента охраны здоровья и безопасности труда. Разъяснение персоналу предприятия требований политики в сфере охраны здоровья и безопасности труда, других документов менеджмента. Период этапа определяется готовностью персонала предприятия к нововведениям, ориентированности руководящего состава на реализацию проекта, а также сложностью структуры организации, выделенного бюджета для действий и материально-техническим оснащением предприятия

\section{5 Внутренний аудит, анализ системы менеджмента охраны здоровья и безопасности труда}

5.1 Проведение стажировки внутренних аудитов $\quad$ Получение внутренними аудиторами практического опыта выполнения аудитов

5.2 Анализ системы менеджмента охраны здоровья и безопасности труда со стороны руководства высшего звена

Оценка достаточности и эффективности системы менеджмента охраны здоровью и безопасности труда по отношению к требованиям стандарта

Итоговый отчет по итогам анализа системы менеджмента со стороны руководителей

\section{6 Аудит системы менеджмента охраны здоровья и безопасности труда перед выдачей сертификата}

6.1 Оценка построенной системы менеджмента в границах выполнения аудита

\begin{tabular}{|c|}
\hline $\begin{array}{l}\text { Оценка готовности системы менеджмента к осуществлению } \\
\text { сертификации, подготовка сотрудников организации для } \\
\text { реализации аудита }\end{array}$ \\
\hline ыполнению ауд \\
\hline
\end{tabular}

6.2 Методическое содействие при определении корректирующих действий по итогам аудита по улучшению 
здоровья и безопасности труда.

В случае положительного заключения сертифицирующего органа будет принято решении о сертификации производства по одной из схем сертификации (в зависимости от уровня подготовки, знаний, опыта и потребностей кандидата):

1. Сертификация ISO 45001 Foundation - сертификация для профессионалов, которым необходимо иметь полное представление о стандарте ISO 45001 и его требованиях [4].

2. Сертификация ISO 45001 - сертификация для профессионалов, которым необходимо внедрить систему менеджмента охраны здоровья и безопасности труда, а в случае сертификации исполнителя ISO 45001 - для управления проектами внедрения [4].

3. Сертификация ISO 45001 - удостоверение профессионалов, которым необходимо проводить аудиты системы менеджмента охраны здоровья и безопасности труда, а в случае сертификации ведущего аудитора ISO 45001 - управлять командой аудиторов [4].

4. Сертификация ISO 45001 Master - профессиональная сертификация для профессионалов, которым необходимо внедрить систему менеджмента охраны здоровья и безопасности труда, овладеть методами аудита и управлять аудиторскими груп- пами или программами аудита (или участвовать в них) [4].

Основываясь на общем профессиональном опыте кандидата и полученной им квалификации, ему будет предоставлен один или несколько сертификатов на основании проекта или аудиторской деятельности, выполненной ранее или выполняемой в настоящее время.

\section{Выво $\Delta ы$}

Внедрение стандарта ISO 45001 на предприятии позволит повысить уровень безопасности труда работников, снизить профессиональные и управленческие риски. Кроме того, совместимость ISO 45001 с другими международными стандартами гарантируют высокоэффективную интеграцию обновленной системы управления охраной труда в систему менеджмента. Учитывая, что первая версия стандарта опубликована в 2018 году, обновленная в 2020 году, можно с уверенностью сказать, что он соответствует текущим реалиям и особенностям организации производств, связанных со сложностью и многоэтапностью технологических процессов, частичной организацией работы в дистанционном формате.

Исследование выполнено при финансовой поддержке ИжГТУ имени М.Т. Калашникова в рамках научного проекта № ШРО/20-86-11.

\section{ЛИТЕРАТУРА}

1. L. Morgado F.J.G. Silva L.M. Fonseca. Mapping Occupational Health and Safety Management Systems in Portugal: outlook for ISO $45001: 2018$ adoption / F.J.G. Silva // Procedia Manufacturing — 2019. — Vol 38. — P. 775-764. https://doi.org/10.1016/j.promfg.2020.01.103

2. A. Sklad. Assessing the impact of processes on the Occupational Safety and Health Management System's effectiveness using the fuzzy cognitive maps approach / A. Sklad // Safety Science — 2019. — Vol 117. — P. 71-80. https://doi.org/10.1016/j.ssci.2019.03.021

3. P.P. Purpura. Safety in the Workplace / P.P. Purpura // Security and Loss Prevention (Seventh Edition) — 2019. — P. 435-455. https://doi.org/10.1016/B978-0-12811795-8.00014-X

4. ГОСТ Р ИС0 45001-2020 «Системы менеджмента безопасности труда и охраны здоровья. Требования и руководство по применению» утвержден и введен в действие Приказом Федерального агентства по техническому регулированию и метрологии от 28 августа 2020 г. N $581-$-ст.

5. ГОСТ P 54934-2012/0HSAS 18001:2007 «Системы менеджмента безопасности труда и охраны здоровья. Требования» утвержден и введен в действие Приказом Федерального агентства по техническому регулированию и метрологии от 6 июля 2012 г. N 154-ст.

6. C.U. Madsen, M.L. Kirkegaard, J. Dyreborg, P. Hasle. Making occupational health and safety management systems 'work': A realist review of the 0 HSAS 18001 standard / C. U. Madsen // Safety Science — 2020. — Vol 129. https://doi.org/10.1016/j.ssci.2020.104843

7. ISO 45001:2018 и OHSAS 18001:2007 - основные отличия [Электронный ресурс]. Режим доступа: https://certificant.org/iso-450012018-i-ohsas-180012007osnovnye-otlichiya/.

8. .Н. Элширкызы. Сравнительный анализ стандарта ISO 45001:2018 и стандарта OHSAS 18001:2008 / Ж.Н. Элширкызы // Гуманитарный трактат — 2019. - № 46. - P. 28-31.

9. В.А. Качалова. 0 примерах улучшений в стандартах ISO 9001:2015, ISO 14001:2015 И ISO 45001:2018 / В.А. Качалова // Методы менеджмента качества — 2019. — № 9. - P. 52-54.

10. T. Karkoszka. Operational monitoring in the technological process in the aspect of occupational risk / T. Karkoszka // Procedia Manufacturing — 2017 . — Vol 13. — P. 1463-1469. https://doi.org/10.1016/j.promfg.2017.09.192 